\title{
Electron-Deficient Molybdenum/Cobalt/Sulfido Clusters: Chemistry Related to Hydrodesulfurization (HDS) Catalysis
}

\section{David Curtis ${ }^{1.2}$}

\author{
Received Febriary 16, 1996
}

\begin{abstract}
The author's work on the reactions of $\mathrm{Cp}_{2} \mathrm{Mo}_{2} \mathrm{CO}_{2} \mathrm{~S}_{3}(\mathrm{CO})_{4}(1)$ and $\mathrm{CP}_{2} \mathrm{Mo}_{2}$ $\mathrm{Co}_{2} \mathrm{~S}_{4}\left(\mathrm{CO}_{2}(2)\right.$ with organosultur compounds is reviewed. Reaction pathways that lead to C $\mathrm{S}$ bond scission are proposed, and the relevance of these results to HDS reactions over commercial "CoMoS" catalysts is discussed.
\end{abstract}

KEY WORDS: Hydrodesulfurization: HDS: catalysis: C.S bond homolysis: mechanism: $\mathrm{Mo} / \mathrm{Co} / \mathrm{S}$ clusters.

\section{INTRODUCTION}

In the last several years, our research group has investigated the chemistry of the $\mathrm{Mo} / \mathrm{Co} / \mathrm{S}$ clusters 1 and 2 as it pertains to hydrodesulfurization (HDS) catalysis. The latter process is used worldwide to remove sulfur from fossil fuels in order to utilize the sulfur-rich, high-boiling residues obtained from the initial distillation of lighter fractions [1-3]. The catalysts normally used in the industrial HDS process consists of a mixture of Mo and Co sulfides and oxides supported on high surface-area $y$-alumina. In recent years, an extensive battery of new spectroscopic techniques have been applied to determine the nature of the $\mathrm{Mo} / \mathrm{Co} / \mathrm{S}$ HDS catalyst $[4,5]$. The model that presently enjoys widepsread acceptance is the "CoMoS"-phase model developed primarily by Topsoe and co-workers.

According to the Topsoe model, the HDS catalyst consists of small MoS,-like crystallites on the alumina surface. The number of Mo-Mo next-nearest neighbors, as determined by EXAFS spectroscopy, suggests that these crystallites are only ca. $10 \mathrm{~A}$ in diameter. The Co-promoter atoms are believed to bind to the edges of the $\mathrm{MoS}_{2}$ layers around the

\footnotetext{
1 Deparment of Chemistry, The University of Michigan. Ann Arbor. Michigan $48109-1055$.

"To whom correspondence should be addressed.
} 


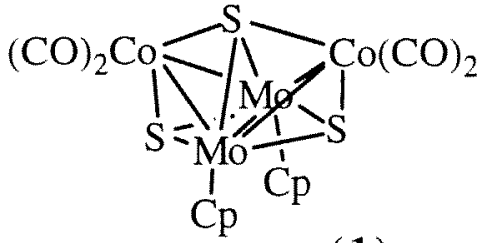

(1)

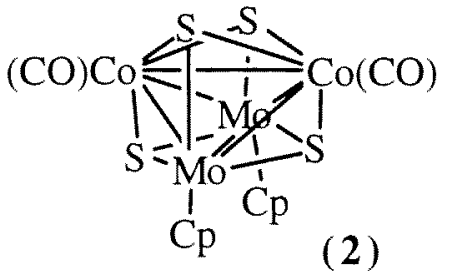

(2)

periphery of the $\mathrm{MOS}_{2}$ crystallite. Several studies have shown that the basal planes of bulk $\mathrm{MoS}_{2}$ are, indeed, unreactive and that Co is preferentally deposited on the edges of the basal planes of the $\mathrm{MoS}_{2}$ crystals [4,6-8]. However, high resolution electron microscopy (HREM) shows that the supported $\mathrm{MoS}_{2}$ forms a highly irregular structure (the so-called "rag" structure) that exhibits folds and bends of the $\mathrm{MoS}_{2}$ sheets [1]. The inevitable defect sites at such folds and kinks may also be the loci of Co adsorption on the $\operatorname{MoS}_{2}$ phase(s).

Even if this physical model of the active sites of the $\mathrm{Co} / \mathrm{Mo} / \mathrm{S} \mathrm{HDS}$ catalyst is correct, the function of the Co promoter is not immediately obvious, nor does this model answer questions, e.g., what are binding modes and loci of the organosulfur substrates? It is in this arena that organometallic modeling can be most valuable. Indeed, research by Angelici [9], Rauchfuss [10], Jones [11], Rakowski-Dubois [12], and Booman [13] has shed much new information on possible thiophene binding modes, mechanisms of $\mathrm{C}-\mathrm{S}$ bond activation, and reactions at coordinated sulfur centers. Bianchini and co-workers have recently made exciting progress in demonstration of homogeneous catalysis of the HDS reaction [14].

This article will review some of our recent work on the chemistry of clusters $\mathbf{1}$ and $\mathbf{2}$ and will present also some new results with 58 VSE (valence shell electron) clusters.

\section{ELECTRONIC STRUCTURE CONSIDERATIONS}

Extended Hückel MO (EHMO) calculations on cluster 1 and similar clusters suggest that the 3s-electrons on the S-atom are sufliciently low in energy that they are not used appreciably in the $M-S$ bonding [15a]. Thus, we consider the neutral S-atom as a 4-electron donor, which means that both 1 and 2 are 60 VSE clusters. Since cluster 1 has only 5 M-M bonds, 1 may be considered to be electron deficient since it lacks two electrons appropriate for a "butterlly," 62 VSE cluster [15]. Indeed, EHMO calculations suggest that the $\mathrm{Co}-\left(\mu_{4}-\mathrm{S}\right)-\mathrm{Co}$ interaction is a 2-electron, 3 -center bond [15a]. On conversion of 1 to 2 , two CO-groups are lost and one $\mathrm{S}$-atom is gained, so the electron count remains at 60 . However, 2 has six $\mathrm{M}-\mathrm{M}$ bonds and is electron precise [16]. 


\section{S-ABSTRACTION REACTIONS BY CLUSTER 1}

Cluster 1 reacts with a wide variety of sulfur-containing organic molecules to give cluster 2 and the desulfurized organic [17] (Scheme 1).

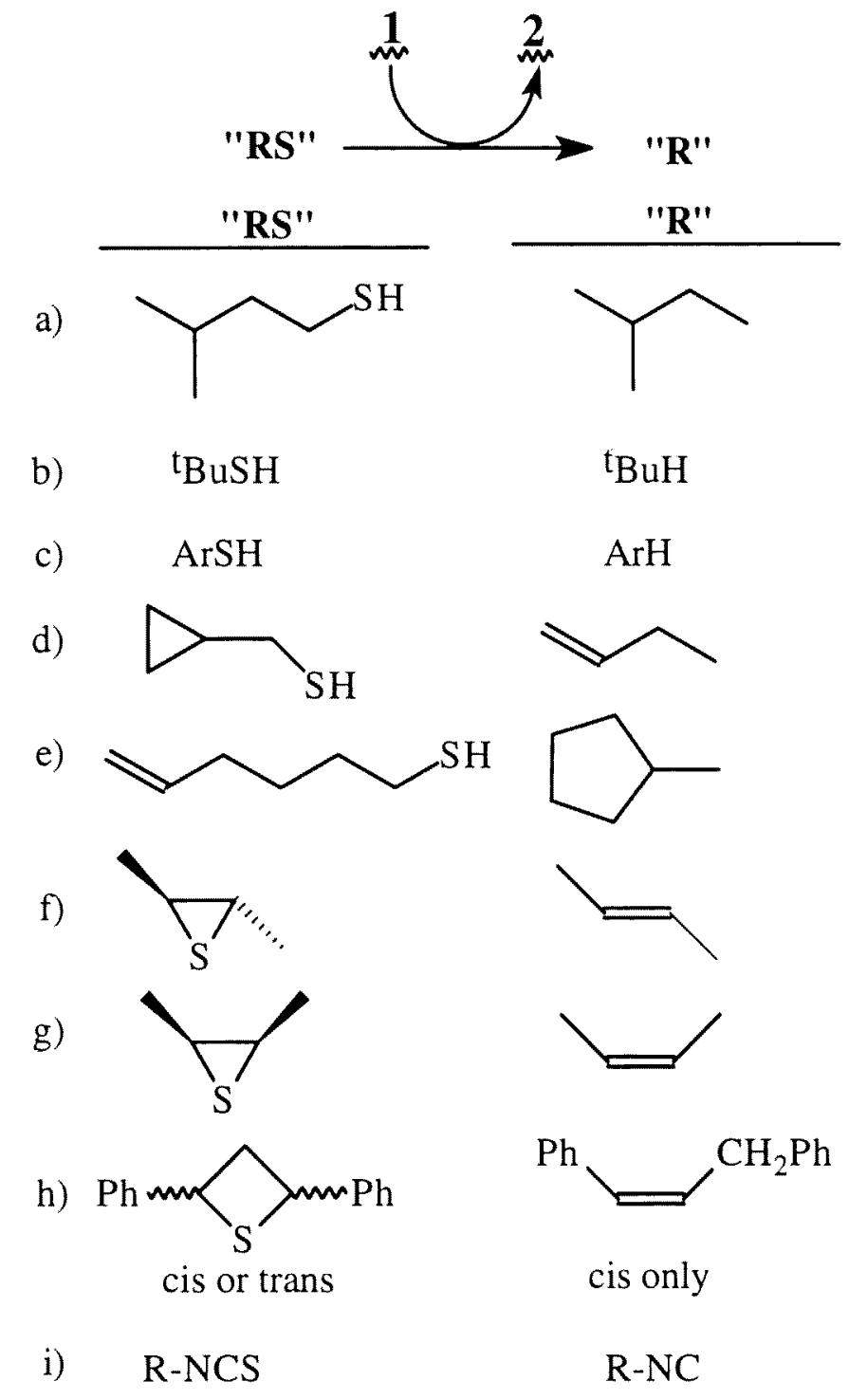


The reactions of branched or linear alkyl thiols with 1 give quantitative yields (NMR) of the corresponding alkane. No alkene or rearranged alkane are observed when the reaction is conducted in a sealed NMR tube. Thus carbocations are not generated during the S-abstraction reaction. The S-abstraction from cis- or trans-2-butene sulfide was stereospecific. However, the desulfurization of 2,4-diphenylthietane is stereoselective: cis-1,3diphenylpropene is the sole organic product from either cis- or transthietane [18]. Rearrangements characteristic of organic free radicals are observed in the desulfurization of cyclopropylmethyl thiol [19] and 6-mercaptohexene (see entries $d$ and $c$ in Scheme 1) [20].

There are some puzzling facets to the results summarized in Scheme 1. Aryl thiols appear to undergo desulfurization at a rate not appreciably different from the alkyl thiols in spite of a significantly larger $\mathrm{C}-\mathrm{S}$ bond strengths in the former. Also, the strong $\mathrm{C}=\mathrm{S}$ double bonds in isothiocyanates undergo rapid desulfurization reactions (entry $i$, Scheme 1 ). It would thus appear that the rate determining step in these reactions does nor involve $\mathrm{C}-\mathrm{S}$ bond breaking. This conclusion was shown to be correct by kinetic studies.

The electronically unsaturated complex 1 was shown to react with phosphines or isocyanides in an associative manner [21]. The general mechanism for CO substitution on cluster 1 is shown in Scheme 2 with a typical activation energy. Under more forcing conditions, a second substitution on the $\mathrm{Co}(\mathrm{CO})_{2}$ vertex may be effected; and up to three carbonyl ligands may be replaced with chelating diphosphines or organic isocyanides [2lb]. In the case of $\mathrm{L}=\mathrm{Me}_{3} \mathrm{P}$, the intermediate 3 was isolated and structurally characterized. The displacement of the $\mathrm{CO}-\mathrm{S}$ bond in $\mathbf{1}$ to form 3 is consistent with our EHMO calculations that portray the $\mathrm{Co}-\mathrm{S}-\mathrm{Co}$ bonding as a $3 \mathrm{c}$ 2e interaction that gives a bond order of 0.5 to each $\mathrm{Co}-\mathrm{S}$ bond. Furthermore, the intermediate 3 is now an electronically saturated, 62 VSE cluster.
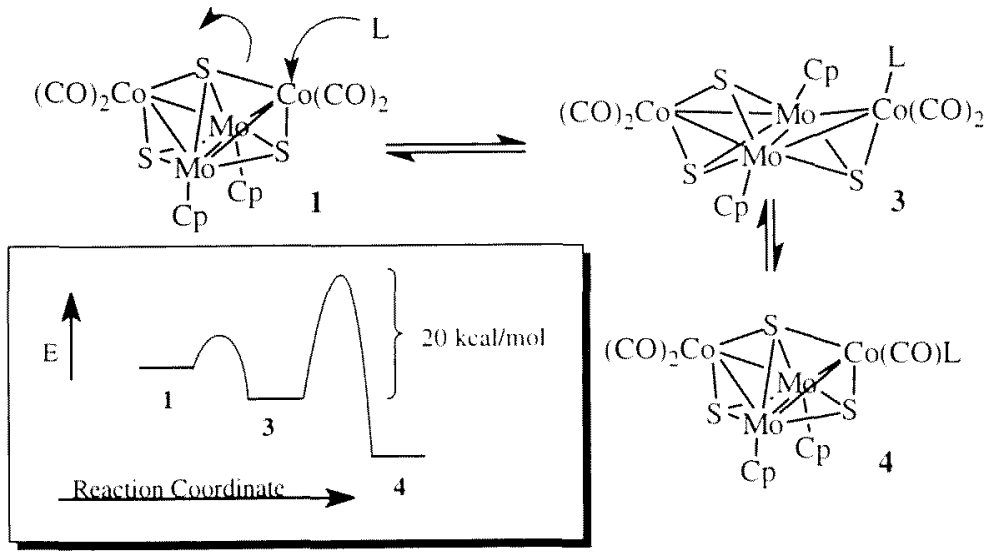

Scheme 2

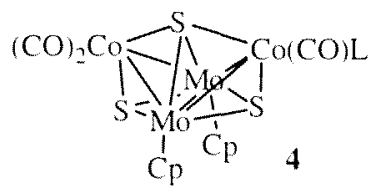


The reaction of thiols with 1 was also shown to be associative with the rate law shown in Eq. (1) [19]. The rate was unaffected by the presence of added $C O$. Electron donating groups, $X$, accelerated the reaction while electron withdrawing groups decelerated it. The activation energies followed a similar trend and had values near $20 \mathrm{kcal} / \mathrm{mol}$. Hence, $20 \mathrm{kcal} / \mathrm{mol}$ must be the upper limit to the $\mathrm{C}-\mathrm{S}$ bond dissociation energy for the reaction shown in Eq. (1). The C- S bond energy in aromatic thiols is near $80 \mathrm{kcal} / \mathrm{mol}$ [22]. Thus, coordination of the thiol to the $\mathrm{Mo} / \mathrm{Co} / \mathrm{S}$ cluster, 1 , causes a nearly four-fold decrease in the $\mathrm{C}-\mathrm{S}$ bond energy!

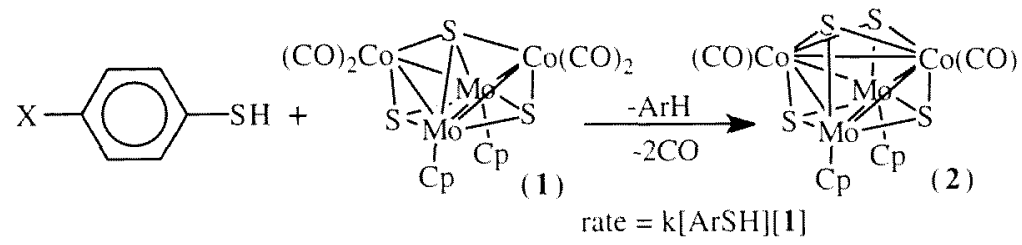

If the rate-determining step in the desulfurization of thiols, as exemplified by Eq. (1), is the initial attachment of the thiol to the cluster by an associative mechanism, then we reasoned that the reactions of the more nucleophilic thiolate anions with cluster 1 would proceed under milder conditions and would allow us to study in more detail the $\mathrm{C}-\mathrm{S}$ bond scission step. We found that aryl thiolate anions react rapidly with cluster 1 at $-60^{\circ} \mathrm{C}$ to generate a deep red intermediate similar to the phosphine adduct, 3 . The NMR spectrum of the $\mathrm{Cp}^{\prime}\left(=\mathrm{C}_{5} \mathrm{H}_{4} \mathrm{Me}\right)$ derivative clearly showed that this intermediate has a plane of symmetry that contains the two Co-atoms and bisects the Mo-Mo bond, i.e., this adduct appears to have the structure 3 (Scheme 1, L = ArS ). As this solution was warmed to $-25^{\circ} \mathrm{C}$, the color became dark green and the NMR spectrum showed two $A B C D$ patterns for the $\mathrm{Cp}-\mathrm{H}$ protons and two singlets for the Me-protons, a spectrum that corresponds to a species with only $C_{1}$ symmetry. We believe that the thiolate has gone from a terminal mode of coordination in 5 to a bridging mode in $6(\mathrm{Eq}$. 2). This rearrangement reaction is preferred by the thiolate adduct over the CO substitution as shown in Scheme 2, although a trace amount of $\mathrm{CO}$ substitution product was isolated and structurally characterized ( $\mathrm{Eq} .3$ ).

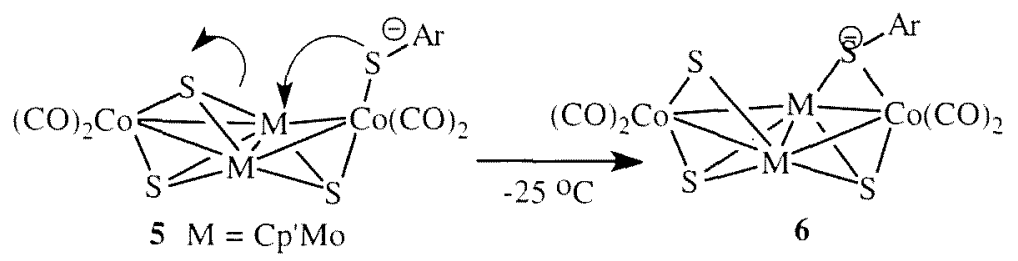






Near $0^{\circ} \mathrm{C}$, complex 6 becomes fluxional and the thiolate and sulfide ligands appear to execute a windshield-wiper motion that again establishes an effective mirror plane through the Co-atoms (Eq. 4). As the temperature is increased still further, the thiolate/sulfide motion crosses the Mo-Mo bond (Eq. 5). The combined fluxional motions shown in Eqs. (4) and (5) impart an effective $C_{2 v}$ symmetry to the molecule and the NMR spectrum approaches that expected for this symmetry (one Me resonance and one $\mathrm{A}_{2} \mathrm{~B}_{2}$ Cp-proton pattern).

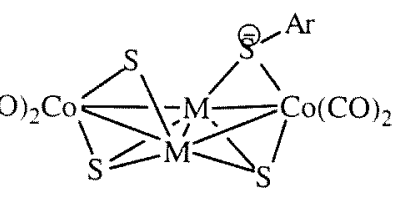

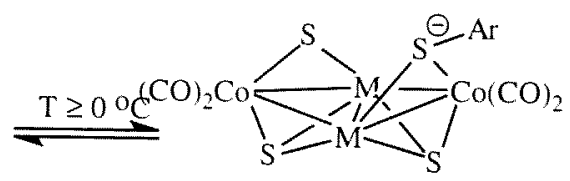

6, $\mathrm{M}=\mathrm{Cp} \mathrm{C}^{\prime} \mathrm{Mo}$
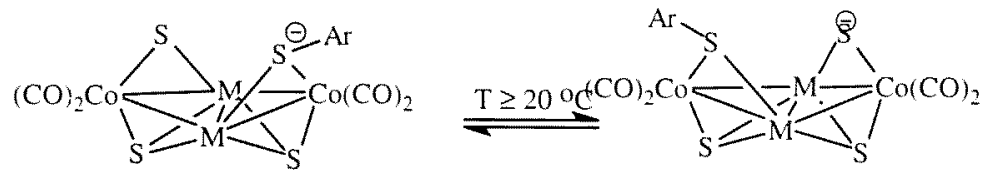

6, $\mathrm{M}=\mathrm{Cp}^{\prime} \mathrm{Mo}$

However, before the fast exchange limit is reached for the process depicted in Eq. (5), the cluster 6 begins to decompose into the paramagnetic cluster 7 (Eq. 6) and the aryl radical, Ar $\bullet$ In deuterated solvent $\left(C D_{3} C N\right)$, the aryl radical abstracts a $\mathrm{D}$-atom from the solvent to give the mono-deuterio arene detected by GCMS of the solution.

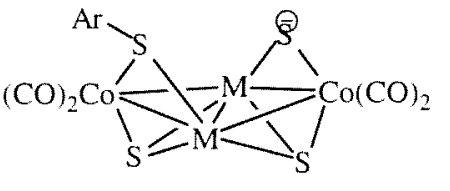

6, $M=C p^{\prime} M o$

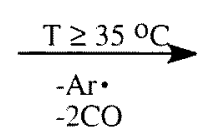

$-\mathrm{Ar}$
$-2 \mathrm{CO}$

The cluster 7 may be prepared also by $\mathrm{Na} / \mathrm{Hg}$-reduction of neutral 2 . The structure of $7[19]$ shows an elongated Co ... Co distance (from 2.56 A in 2 to $2.75 \AA$ in 7$)$. The ESR spectrum of the $\mathrm{Cp}^{*}\left(=\mathrm{C}_{5} \mathrm{Me}_{4} \mathrm{Et}\right)$ analog of 7 is consistent with the odd electron evenly delocalized over two Co 
$(I=7 / 2)$ nuclei. Thus, we believe that the extra electron in 7 is added to the Co-Co $\sigma^{*}$ orbital of 2. Harris [16] has calculated that the LUMO of $\mathrm{M}_{2} \mathrm{M}_{2}^{\prime} \mathrm{S}_{4}$ clusters is metal-metal anti-bonding, so our results are consistent with these calculations.

These results allow us to piece together a self-consistent mechanism for the desulfurization of thiols by cluster 1 . The rate-determining step is the nucleophilic attack of the thiol to give an intermediate, 8 (Scheme 3 ). The terminal thiol can then bend over and bind to the Mo-atom in a $\mu_{2}$-mode (intermediate 9). Intermediate $\mathbf{9}$ has a quaternary sulfur that should render its attached $\mathrm{H}$-atom acidic. Transfer of this proton to the $\mu_{2}$-sulfido ligand gives intermediate 10. Now the thiolate sulfur can bind in a $\mu_{3}$-fashion. We believe it is this $\mu_{3}$-thiolate binding mode that activates the $\mathrm{C}-\mathrm{S}$ bond to homolytic cleavage. $\mathrm{C}-\mathrm{S}$ bond homolysis, followed by $\mathrm{H}$-atom abstraction leads to intermediate 13. Loss of $\mathrm{CO}$ and "folding up" of the cluster gives the ultimate cubane cluster, 2.

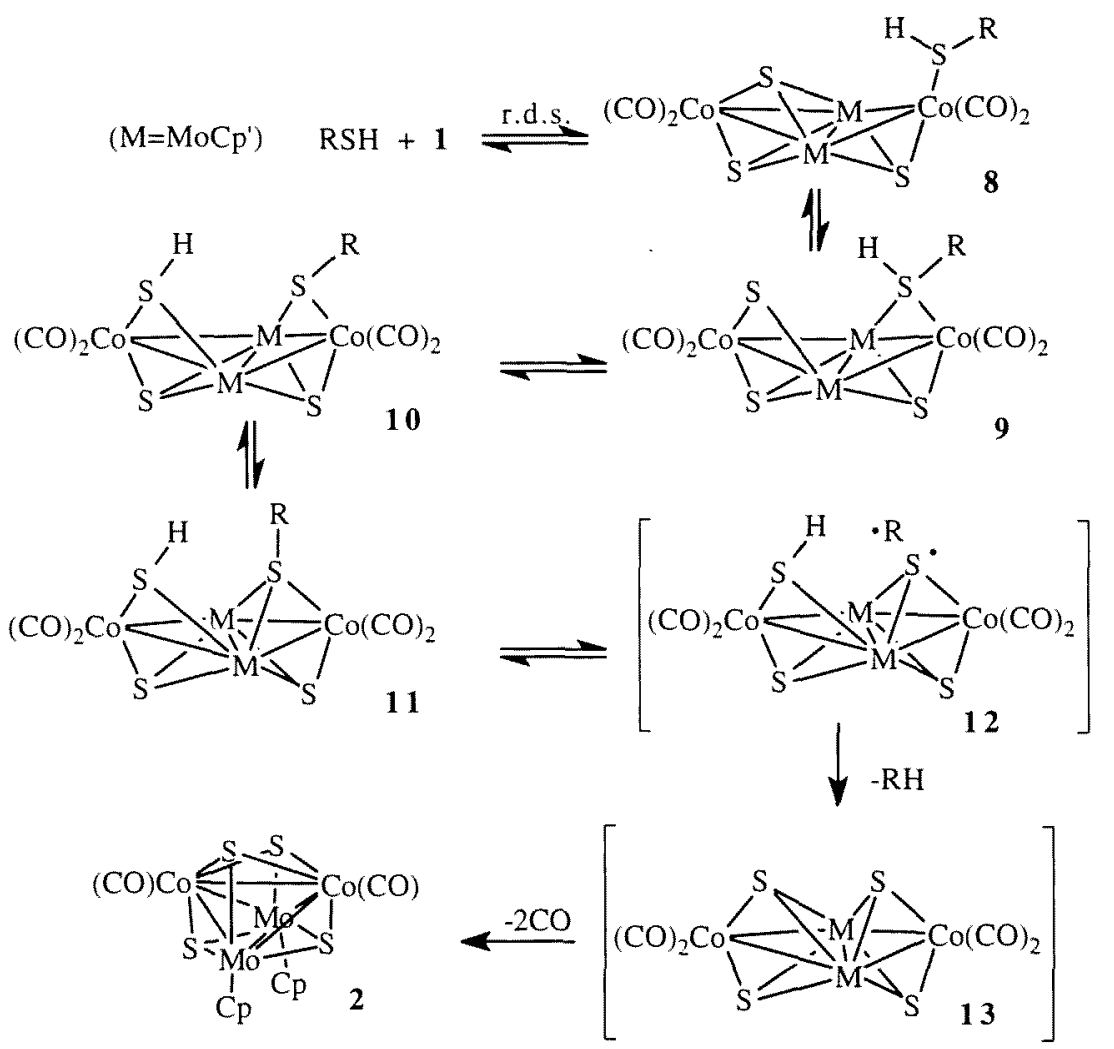

Scheme 3 
A comment about the C-S bond homolysis is perhaps useful. A bond energy is the difference between two thermodynamic states. Thus, if we compare the $\mathrm{C}-\mathrm{S}$ bond energy in the two reactions depicted in Eqs. (7) and (8), relative $\mathrm{C}-\mathrm{S}$ bond energies will depend on the relative energies of HS. radical and the $\mathrm{M}_{3} \mathrm{~S}$ fragment (formally oxidized with respect to the $\mathrm{ArSM}_{3}$ cluster). Since the $\mathrm{S}$-atom in $\mathrm{M}_{3} \mathrm{~S}$ is in a stable bonding mode as

$(\mathrm{M}=\mathrm{MoCp})$
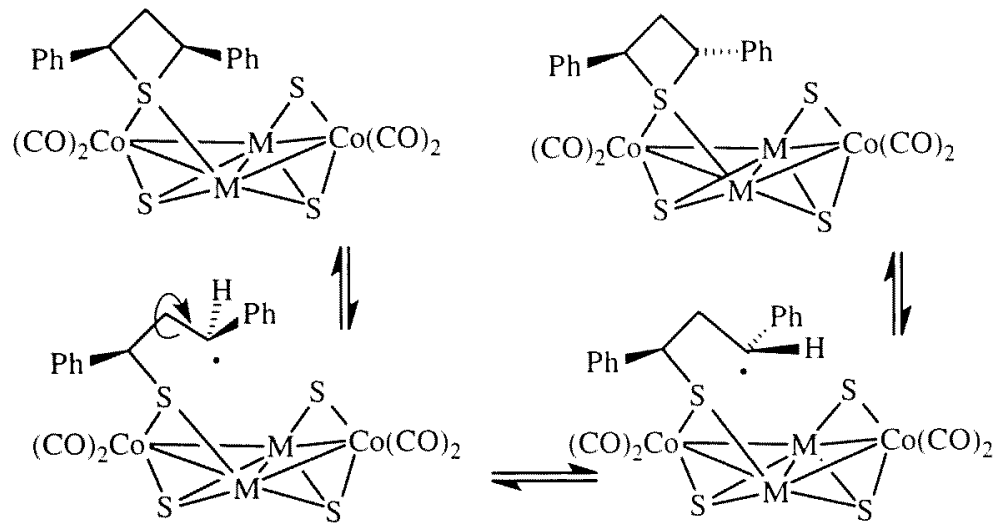

$14 \mathrm{c}$

$14 t$

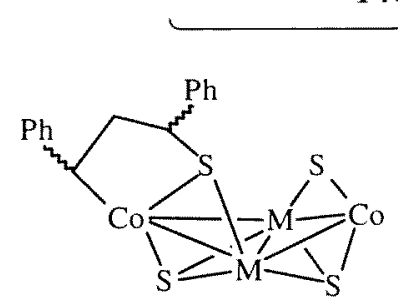

15

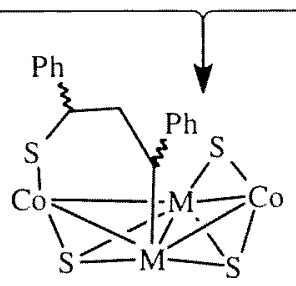

16

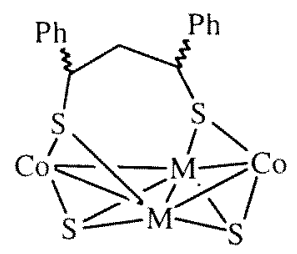

17

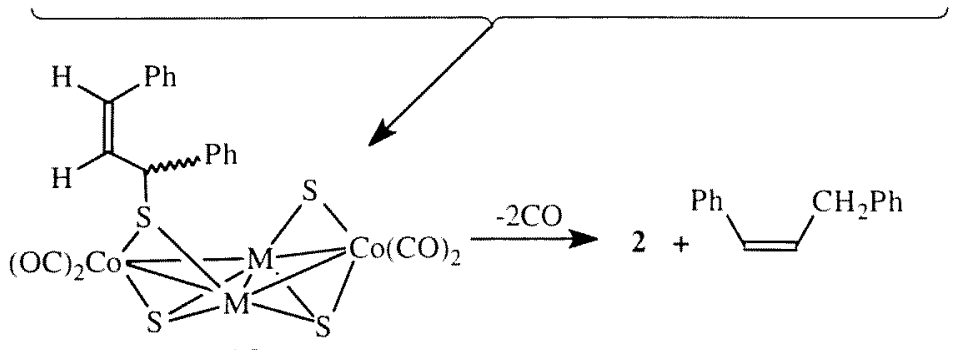

18

Scheme 4 
compared to the unstable $\mathrm{SH}$ radical, the apparent $\mathrm{Ar}-\mathrm{S}$ bond energy is greatly decreased in cluster-bound thiolate and $\mathrm{C}-\mathrm{S}$ homolysis is thermally accessible.

\section{$\mathrm{Ar}-\mathrm{SH} \longrightarrow \mathrm{Ar} \cdot+\cdot \mathrm{SH}$}

A slight variation on the mechanism shown in Scheme 3 can account for the thietane results shown as entry " $h$ " in Scheme 1. Coordination of the thietane, followed by homolytic $\mathrm{C}-\mathrm{S}$ bond scission could form one or more of the thiametallacycle types, 15-17, shown in Scheme 4. Rotation about the $\mathrm{C}-\mathrm{C}$ bond of the ring-opened thietane, $(14 \mathrm{c} \Leftrightarrow 14 \mathrm{t})$ followed by ring closure and dissociation of the thietane would give a mechanism for $c i s \Leftrightarrow t r a n s$ isomerization of the unreacted theietane, a process that we have observed.

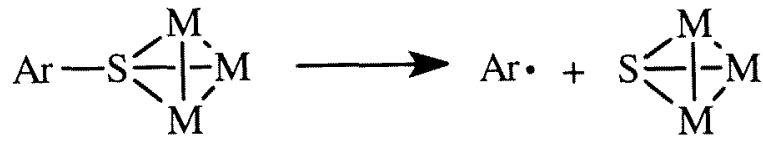

The proposed formation of metallacycles 15-17, and the mechanism of thietane isomerization finds support in the results of Adams et al. [23]. These workers have isolated and characterized cis- and trans-thiametallacycles of 2,4-diphenylthietane with an $\mathrm{Os}_{3}$ cluster, and have observed the isomerization of the trans- to the cis-isomer. They also postulate a mechanism that involves $\mathrm{C}-\mathrm{S}$ bond homolysis.

At some point, one (or more?) of the metallacycles $15-17$ must undergo $\beta$-elimination to give a cis-diphenylpropenethiolate complex (18). This thiolate complex can then undergo the $\mathrm{C}-\mathrm{S}$ bond homolysis, H-atom abstraction sequence shown in Scheme 3. It should be pointed out that the stereochemistry of the final product, 1,3-diphenylpropene, is not directly determined by the relative cis- or trans-orientations of the phenyl groups in the thiametallacycles 15-17. Rather, the stereochemistry of the propene product is determined by which of the two H-atoms at the three-position of the thietane ring are eliminated. This in turn will depend on how easily a given stereoisomer of the intermediate thiametallacycle can approach the favored conformation for $\beta$-hydride elimination (a small $\mathrm{MCCH}$ dihedral angle). The orientation of the phenyl groups with respect to the cluster framework undoubtedly has a large influence on this preferred conformation. Figure 1 shows one possible conformation that molecular modeling (MM2) suggests is viable for $\beta$-hydride elimination leading to the $Z$-isomer. Adams et al. found that the cis-thiaosmacyclopentane mentioned 

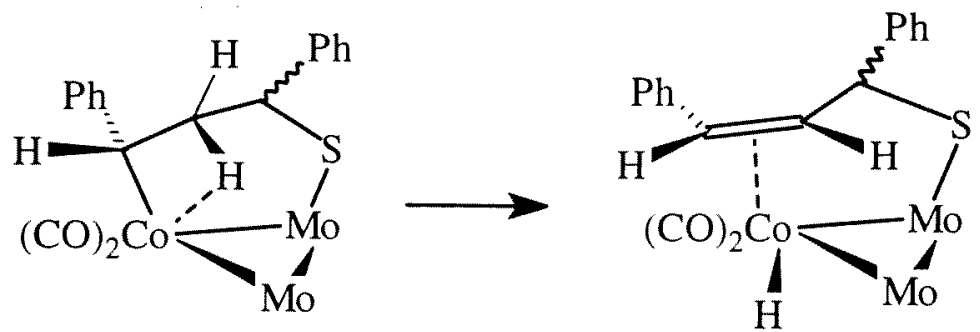

Fig. 1. A possible conformation of the thiametallacycle that leads to a Z-propenethiolate ligand by $\beta$-hydride elimination.

above underwent a $\beta$-hydride elimination to form the trans-1,3-diphenylpropenethiolate ligand [23]. In other words, the conformational preferences in the $\mathrm{Co} / \mathrm{Mo}$ - and $\mathrm{Os}_{3}$-cluster thiametallacycles apparently lead to opposite $\beta$-hydride elimination geometries.

It is interesting to note that blocking the $\beta$-hydride elimination pathway completely changes the course of the reaction of 1 with thietanes. The reaction of 3,3-dimethylthietane with 1 proceeds much more slowly than the reaction with 2,4-diphenylthietane, and the final product, obtained in low yield, is 4,4-dimethylthiabutyrolactone (Eq. 9). The formation of this $\mathrm{CO}$-insertion product strongly suggests the presence of $\mathrm{Co}-\mathrm{C}$ bonds, e.g., in 15, in the reaction sequence. Thiolactone formation from thietanes and $\mathrm{CO} /$ metal carbonyl has been observed previously [24].

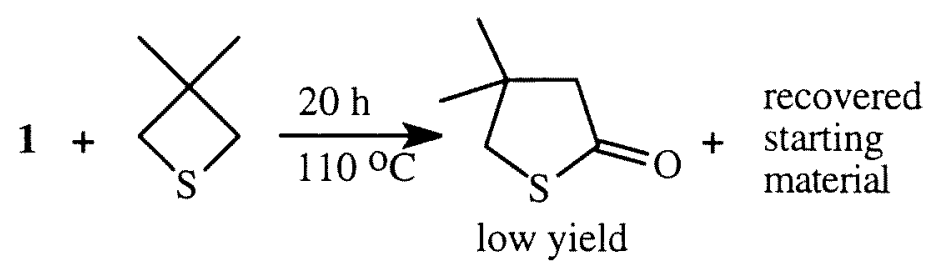

\section{S-ABSTRACTION REACTIONS BY THE CUBANE CLUSTER, 2}

During the studies of the sulfur abstraction from thietanes by cluster 1 , we observed that when a large excess of thietane was employed in the reaction cluster 2 reacted further with the thietane to give an insoluble, black powder that analyzed well for $\mathrm{Cp}_{2} \mathrm{Mo}_{2} \mathrm{CO}_{2} \mathrm{~S}_{5}$. IR spectroscopy shows that the black powder has lost all carbonyl groups. A possible structure for the black powder would be a polymeric or oligomeric chain of cubes linked with sulfide bridges as shown in Eq. (10). 


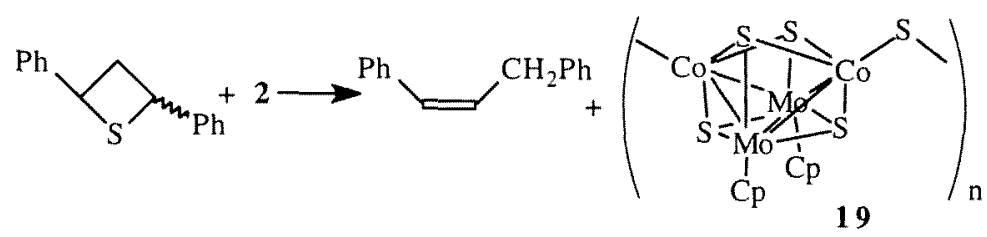

The cubane structure, 19, represents a formal two-electron oxidation of cluster 2. We have therefore sought to model the insoluble compound believed to be 19 by controlled oxidation of the cubane, $\mathrm{Cp}_{2}^{*} \mathrm{Mo}_{2} \mathrm{Co}_{2}$ $\mathrm{S}_{4}(\mathrm{CO})_{2}\left(\mathrm{Cp}^{*}=\mathrm{C}_{5} \mathrm{Me}_{4} \mathrm{Et}\right.$ or $\left.\mathrm{C}_{5} \mathrm{Me}_{5}, 2^{*}\right)$. Cluster $2^{*}$ reacts readily with halogens, diphenyl disulfide, or benzene thiol according to Scheme 5. The products are the 58 VSE clusters $\mathrm{Cp}_{2}^{*} \mathrm{Mo}_{2} \mathrm{CO}_{2} \mathrm{~S}_{4} X_{2}(X=$ halide, SPh $)$. These compounds have molecular structures that differ from that of 2 primarily in the length of the Co... Co distance [25]. In the $60 \mathrm{VSE}$ carbonyl cubane, 2 , the $\mathrm{Co}-\mathrm{Co}$ bond distance is $2.58 \AA$ [26], a distance consistent with the expected presence of a bond between the Co-atoms. In the chloride and iodide clusters, 21 and $\mathbf{2 3}$, the Co ... Co distances are $2.95 \AA$ and $2.93 \mathrm{~A}$, respectively [25]. This increase suggests that in the formal, oxidative conversion of 2 ( or $2^{*}$ ) to the 58 VSE halides, the two electrons are removed from the $\mathrm{Co}-\mathrm{Co} \sigma$-bond. Such a result would not be unexpected based on the theoretical description of the metal-metal bonding in these bimetallic sulfido clusters [16].

Surprisingly, then, the Co ... Co distance, $2.74 \AA$, in the thiolato cluster 20 is only midway between the $\mathrm{Co}-\mathrm{Co}$ bonding distance in $\mathbf{2}$ and the Co ... Co nonbonding distance in $\mathbf{2 1}$ and 23. This intermediate length is nearly identical to that in the radical anion of 2 (see discussion of cluster 7 above). The magnetic properties of $\mathbf{2 0}$ are also different from that of the halide derivatives. The latter exhibit an $S=1$ ground state and thermally accessible $S=2$ and 3 excited states. The former behaves as a simple paramagnet with $\mu=3.49$ B.M. [25].

These modeling studies lend some support to the supposition that the insoluble sulfides obtained in the reaction depicted by Eq. (10) are indeed cubane clusters linked by sulfide bridges. Some additional evidence was sought by attempting to convert the insoluble material back to a characterizable species. The thiolato cluster, $\mathbf{2 0}$, was selected as a model for such reactions. Treatment of 20 with $\mathrm{CO}(400-1000 \mathrm{psi})$ regenerates 2 and produces $\mathrm{PhSSPh}$ (Eq. 11). When the insoluble polysulfide was subjected to these conditions, a $40 \%$ yield of 2 was obtained and COS was detected by $\mathrm{GC} / \mathrm{MS}$ of the head gases. This transformation can be summarized by Eq. (12). Yields higher than ca. $40 \%$ in Eq. (12) have not been realized, suggesting the possibility that only a portion of the insoluble sulfides has 
the structure represented by 19 . However, the far-IR spectrum of the unconverted, insoluble fraction has a peak near $388 \mathrm{~cm}^{-1}$, characteristic of all the $\mathrm{Mo}_{2} \mathrm{M}_{2} \mathrm{~S}_{4}$ cubane clusters examined. It thus appears that even the insoluble fraction retains the cubane cluster geometry. We have no good explanation at this time as to why only ca. $40 \%$ of the solid 19 can be converted to 2 .
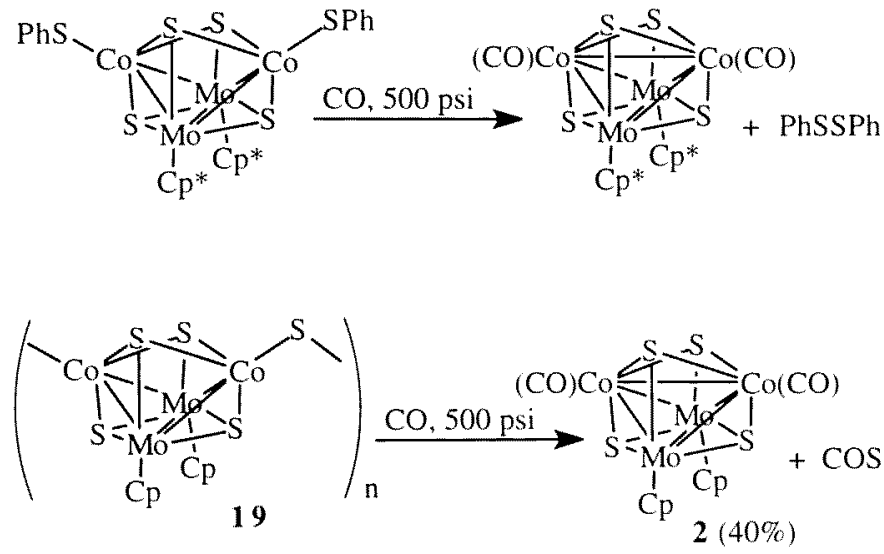

The conversion of $\mathbf{2 0}$ to $\mathbf{2}$ (Eq. 11), combined with the formation of $\mathbf{2 0}$ from $\mathrm{PhSH}$ (Scheme 5), suggests the possibility of a catalytic cycle for the

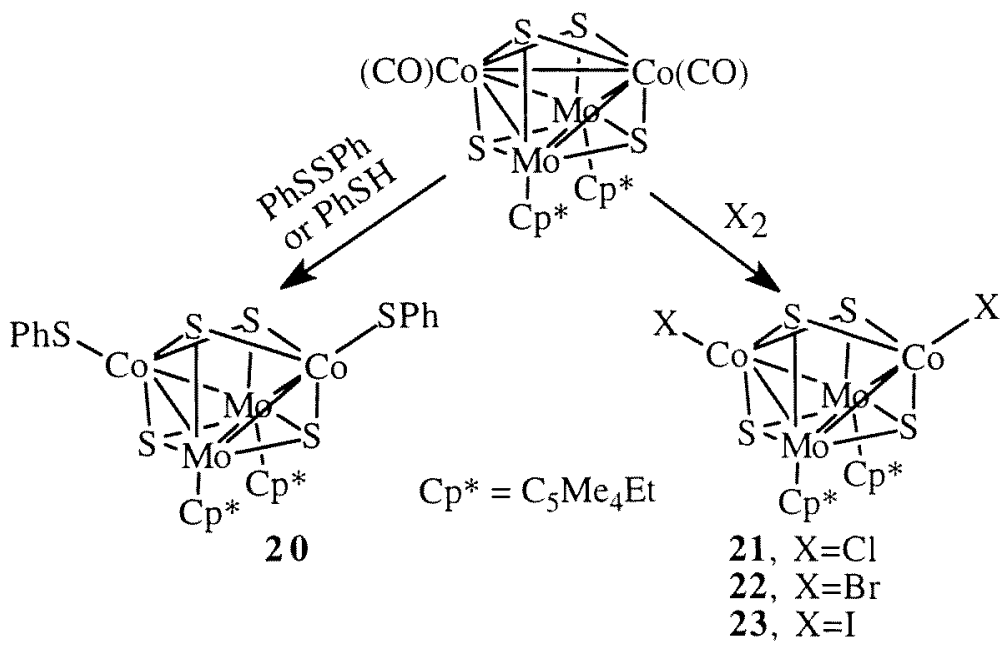

Scheme 5 
conversion of $\mathrm{PhSH}$ into $\mathrm{PhSSPh}$ and $\mathrm{H}_{2}$. This conversion, shown in Scheme 6, was attempted with a 162-fold excess of PhSH under 1000 psi of $\mathrm{CO}$ at $150^{\circ} \mathrm{C}$. The products were $\mathrm{PhSSPh}\left(171 \%\right.$, based on $\left.2^{*}\right)$ and $\mathrm{PhC}(\mathrm{O}) \mathrm{SPh}(161 \%)$. A $56 \%$ yield of $\mathbf{2 0}$ was also recovered along with some of the black, insoluble polymer 19. The PhSSPh was the expected product. The phenyl thiobenzoate was an unexpected product that must arise from a catalytic desulfurization of $\mathrm{PhSH}$, and its formation also suggests that metal-carbon bonds are formed during the desulfurization reaction. We propose that under the high $\mathrm{CO}$ pressure, $\mathrm{CO}$ inserts into a $\mathrm{M}-\mathrm{Ph}$ bond to give an acyl intermediate. This intermediate reacts with excess PhSH to form the thiobenzoate ester (Scheme 6).

The mechanism of the initial desulfurization step shown in the righthand loop in Scheme 6 is at present unknown. Although we show the carbonyl cluster, $2^{*}$, as an intermediate in the catalytic cycles in Scheme 6 , it may be that the participation of $2^{*}$ is not necessary. We have some indications in current work that the 58 VSE, sulfide-linked cubes 19 (Eq. 10) can react with S-donors to form what appear to be polysulfidelinked polymeric compounds. These polysulfides react with the $\mathrm{H}_{2}$ to regenerate 19 along with the formation of $\mathrm{H}_{2} \mathrm{~S}$. Further work is required to determine the role of these polymeric materials with apparent formulas, $\mathrm{Cp}_{2}^{*} \mathrm{MO}_{2} \mathrm{Co}_{2} \mathrm{~S}_{x}(x>5)$.

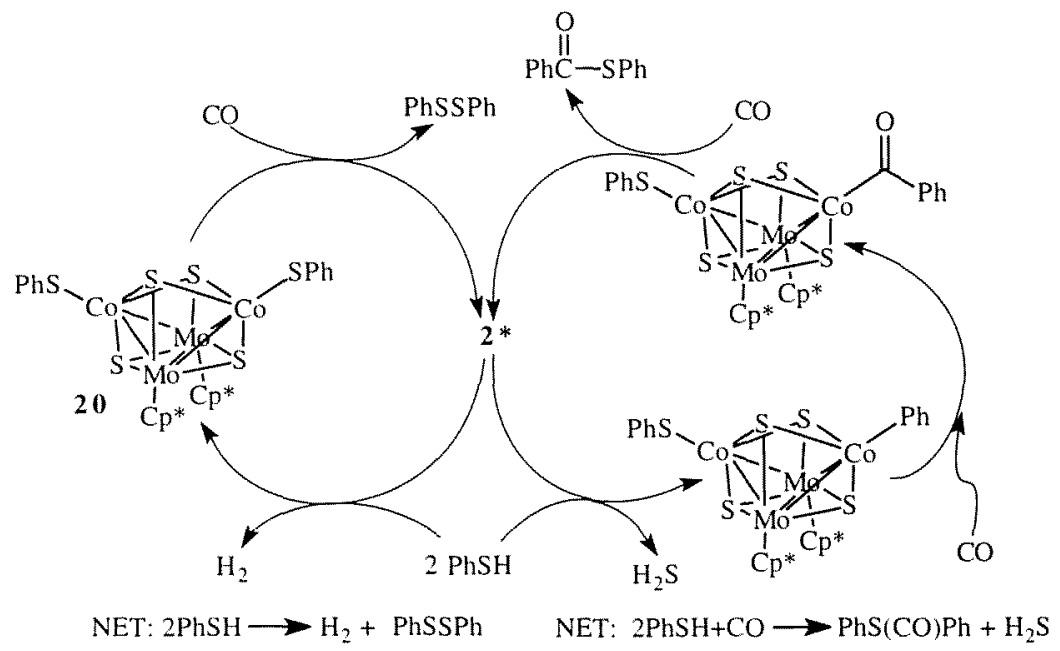

Scheme 6 


\section{RELEVANCE TO HDS CATALYSIS}

The cluster, $\mathrm{Cp}_{2} \mathrm{Mo}_{2} \mathrm{Co}_{2} \mathrm{~S}_{3}(\mathrm{CO})_{4} \mathbf{1}$, may be considered to be electronically unsaturated with 60 VSE if the S-atoms are taken as four-electron donors. Cluster 1 reacts with two-electron donor ligands to form adducts or intermediates that lead to further reaction, e.g., $\mathrm{CO}$ displacement or S-atom abstraction. This electronic unsaturation, combined with a demonstrated mobility of sulfur ligands on the "surface" of the cluster (see Scheme 3 and Eqs. 2-6), allow for the "generation" of transient, open coordination sites for organic sulfides. Thus, a variety of coordination sites can be generated while maintaining favorable electron counts in the intermediate species. The ability to maintain favorable electron counts may lower the activation energies of these processes, thus accounting for their relatively rapid reaction rates under mild conditions.

Furthermore, $\mu_{2}$ - or $\mu_{3}$-binding of organosulfur substrates to the cluster "surface" activates the $\mathrm{C}-\mathrm{S}$ bond to homolytic cleavage. $\mathrm{C}-\mathrm{S}$ bond homolysis has been observed previously by Adams ef al. on $\mathrm{Os}_{3}$ clusters where similar multipoint bonding occurs $[23,27]$, but this mode of $C-S$ bond breaking has not received much attention as a possible reaction path in HDS catalysis. More attention has been focused on oxidative addition to the $\mathrm{C}-\mathrm{S}$ bond or nucleophilic displacement of sulfur.

$\mathrm{C}-\mathrm{S}$ bond homolysis has been proposed as the reaction path followed by thiolates on clean metal surfaces [28]. Since $\mu_{2}$ - and $\mu_{3}$-bonding are certainly possible on HDS catalyst surfaces, homolytic C-S scission is also a possible mechanism in HDS catalysis. The low activation energy that we have observed for this process furthermore suggests that $\mathrm{C}-\mathrm{S}$ bond cleavage is probably not the rate determining step in HDS reactions conducted at $350^{\circ} \mathrm{C}$ and above. Rather, cleaning the metal surface, i.e., removal of sulfide as $\mathrm{H}_{2} \mathrm{~S}$, to regenerate vacant coordination sites for substrate adsorption is most likely the slow step under actual catalytic conditions. This conclusion is consistent with some kinetic studies that suggest the release of $\mathrm{H}_{2} \mathrm{~S}$ is the kinetically controlling step in heterogeneous HDS catalysis [29]. A recent theoretical paper on HDS reactions occurring on $\mathrm{Ni} / \mathrm{S}$ clusters concluded that $\mathrm{C}-\mathrm{S}$ bond scission and sulfur removal from the cluster compete for the role of rate-determining-step in catalytic HDS [30].

Finally, the results obtained with the $\mathrm{Mo} / \mathrm{Co} / \mathrm{S}$ clusters suggest a role for the Co "promoter" effect. The weaker $\mathrm{Co}-\mathrm{S}$ bond may act as a "masked" vacant site. That is, although the Co atom may be coordinated to sulfur, the $\mathrm{Co}-\mathrm{S}$ bond is capable of being displaced by the substrate as illustrated in Scheme 3. The utilization or unmasking of such sites will depend, inter alia, on the ability of the incoming nucleophile to displace the 
bound sulfur from the cobalt. This phenomenon may be the root of the difficulty in determining the number of active sites on metal sulfide catalysts by chemisorption [31]. The number of sites found will depend on the reagent used to titrate them. Both $\mathrm{O}_{2}$ and $\mathrm{NO}$ have been used, but the number of sites determined depends strongly on the chemisorption conditions.

The $\mathrm{Mo} / \mathrm{Co} / \mathrm{S}$ clusters described in this paper appear to mimic many aspects of HDS catalysis by the CoMoS catalyst used commercially. Catalytic sulfur removal has been demonstrated under $\mathrm{CO}$, but the mechanism of this reaction has not been established. The conversion of cubane $\mathbf{2}$ back to $\mathbf{1}$ is the cluster analog of cleaning the catalyst surface in preparation for the next turnover, and this process is more difficult than $\mathrm{C}-\mathrm{S}$ bond breaking. Current work is aimed at finding clusters that "release" sulfur as $\mathrm{COS}$ or $\mathrm{H}_{2} \mathrm{~S}$ more readily.

\section{ACKNOWLEDGMENTS}

The author thanks his present and former students who are acknowledged in the references for their dedication and original contributions. The work described here was supported by the National Science Foundation (USA) under grant numbers, CHE-9205018 and CHE-9523056.

\section{REFERENCES}

1. R. R. Chianelli. M. Daage, and M. J. Ledoux (1994). Adv. Catal. 40, 177-232.

2. H. L. Hoffman (1991). Hydrocab. Proc: 70, 37.

3. F. E. Massoth (1978). Adt. Catal. 27, 265.

4. H. Topsøe and B. S. Clausen, Catal. Ret.-Sci. Eng. 26, 395.

5. R. Prins, V. H. J. de Beer, and G. A. Somorjai (1989). Catal. Ret,--Sei. Eng. 31, 1.

6. C. B. Roxlo, M. Daage, A. F. Ruppert, and R. R. Chianelli (1986). J. Catal. 100, 176.

7. R. R. Chianelli, A. F. Ruppert, S. K. Behal, B. H. Kear, A. Wold, and R. Kershaw (1985). J. Catal. 92, 56.

8. M. J. Ledoux, Y. Segura, and P. Pannisod (1990). ACS Diw. Petrol. Chem. Prepr. Papers 35, 217.

9. R. J. Angelici (1988). Review. Accts. Chem. Res. 21, 387.

10. T. B. Rauchfuss (1991). Prog. Inorg. Chem. 39, 260.

11. (a) W. D. Jones and R. M. Chin (1992). Organometallics 11, 2698; (b) C. P. Rosini and W. D. Jones (1992). J. Am. Chem. Soc. 114, 10767; (c) L. Dong. S. B. Duckett, K. F. Ohman, and W. D. Jones (1992). J. Am. Chem. Soc. 114, 151; (d) W. D. Jones and R. M. Chin (1992). J. Am. Chem. Soc. 114, 9851; (e) W. D. Jones and R. M. Chin (1994). J. Am. Chem. Soc. 116, 198.

12. M. Rakowski Du Bois (1989). Review. Chem. Ret. 89. 1.

13. P. M. Boorman, X. Gao, J. F. Fait, and M. Parvez (1991). Inorg. Chem. 30, 3886.

14. (a) C. Bianchini, A. Meli, M. Peruzzini, F. Vizza, P. Frediani, V. Herrera, and R. A. Sanchez-Delgado (1993). J. Am. Chem. Soc. 115, 2731; (b) C. Bianchini, A. Meli, 
M. Peruzzini, F. Vizza. P. H. Frediani, and R. A. Sanchez-Delgado (1993). J. Am. Chem. So, 115, 7505: (c) C. Bianchini, A. Meli, M. Perizzini. F. Vizza. V. Herrera, and R. A. Delgado (1994). Organometallics 13, 721: (d) C. Bianchini. A. Meli. M. Peruzzini. F. Vizza. S. Moneti. V. Herrera, and R. A. Sanchez-Delgado (1994). J. Am. Chem. Soc. 116. 4370 .

15. (a) P. Li and M. D. Curtis (1990). Inorg. Chem. 29, 1242; (b) M. D. Curtis and P. D. Williams (1983). Inorg. Chem. 22, 2661.

16. S. Harris (1989). Pollhedron 8, 2843-2882.

17. U. Riaz, O. Curnow, and M. D. Curtis (1991), J. Am. Chem. Sin. 113, 1416.

18. S. H. Druker. M. A. Mansour, D. Sielemann, and M. D. Curtis (to be published).

19. S. H. Druker and M. D. Curtis (1995). J. Am. Chem. Sox. 117, 6366.

20. K. E. Dungey and M. D. Curtis (to be published).

21. (a) O. J. Curnow, J. W. Kampl, M. D. Curtis, J.-K. Shen. and F. Basolo (1994). J. Am. Chem. Soc. 116. 224: (b) M. D. Curtis and O. J. Cumow (1994). Organemetallics 13, 2489.

22. $\mathrm{C} \mathrm{S}$ bond dissociation energy calculated from thermochemical data, in D. Griller, J. M. Kanabus-Kaminsks, and A. J. Maccoll (1988). J. Mol. Strwt. (Theochem.) 163, 125.

23. R. D. Adams and M. P. Pompeo (1992). Orgamemetallies 11. 103,

24. (a) M. D. Wang, S. Calel, and H. Alper (1989), J. Org. Chem. 54, 20; (b) R. D. Adams. J. A. Belinski, and J. H. Yamamoto (1992). Organemetallies 11, 3422.

25. M. A. Mansour, M. D. Curtis, and J. W. Kampl (1995). Orgumemetallies 14. 5460.

26. U. Riaz. O. J. Cumow, J. W. Kampl, and M. D. Curtis (1995). Organomefalles 14, 5337.

27. (a) R. D. Adams (1995). Reviews. Chem. Rer. 95, 2587; (b) R. D. Adams (1985). Polyhedron 4. 2003: (c) R. D. Adams and I. T. Horvath (1985). Prog. Inorg. Chem. 33, 127; (d) R. D. Adams, M. P. Pompeo, W. Wu, and J. H. Yamamoto (1993). J. Am. Chem. Soc. 115. 8207 , and references therein.

28. B. C. Wiegand. P. Uvdal, and C. M. Friend (1992). J. Phy. Chem. 96, 4527.

29. (a) W. R. Moser. G. A. Rossetti. J. T. Gleaves, and J. R. Ebner (1991). J. Caral. 127(1), 190) 200: (b) J. C. DuChet. E. M. Van Oers, V. H. J. DeBeer. and R. Prins (1983), J. Caral. 80. 386: (c) J. P. R. Vissers. V. H. J. DeBeer, and R. Prins (1987). J. Chem. Soc. Farada Trims. $/ 83.2145$.

30. M. Neurock and R. A. van Santen (1994). J. Am. Chem. Soc. 116. 4427.

31. B. J. Carvill and L. T. Thompson (1991), Appl. Catal. 75. 249, and references therein. 